\title{
The Great Lapse: Climate Change, Water Resources and Economic Risks in the Great Lakes
}

\author{
Jenny Kehl \\ University of Wisconsin, Milwaukee, USA \\ Email: jennyjenny411@gmail.com
}

How to cite this paper: Kehl, J. (2018) The Great Lapse: Climate Change, Water Resources and Economic Risks in the Great Lakes. Journal of Water Resource and Protection, 10, 1106-1114.

https://doi.org/10.4236/jwarp.2018.1011065

Received: July 24, 2018

Accepted: November 12, 2018

Published: November 15, 2018

Copyright $\odot 2018$ by author and Scientific Research Publishing Inc. This work is licensed under the Creative Commons Attribution International License (CC BY 4.0).

http://creativecommons.org/licenses/by/4.0/

\section{(c) (i) Open Access}

\begin{abstract}
The striking vastness of the world's largest surface freshwater resource, the Laurentian Great Lakes, has generated the fallacy that they are not highly vulnerable to climate change. This fallacy has created a great lapse in our research and understanding of the effects of climate change on the Great Lakes, which are approaching critical environmental thresholds and jeopardizing ecosystem services. This article takes the novel approach of correcting the disconnect between the perception of vastness and the reality of vulnerability to climate change in the Great Lakes, and takes an additional novel step to link the water risks with the economic risks. The primary purpose is to demonstrate the interdependence of the freshwater ecosystem services affected by climate change with the economies that are highly dependent on those freshwater services in the Great Lakes region. Although many believe that environmental science or ethical arguments should be sufficient to warrant action on climate change, evidence shows that policy-makers are not compelled to generate advances unless there are strong economic components. This article highlights the leading edge of climate science for the Great Lakes, having conducted 32 in depth interviews with experts in microbiology, ecology, and limnology, among others, but it also adds substantively to previous work by providing economic evidence of water risks in the agricultural sector and energy sector, which constitute over $\$ 6$ trillion in value and jobs that are specifically dependent on lakes waters. The article concludes by articulating three specific conclusions: the economic viability of the agricultural sector and the energy sector are jeopardized by loss of federal funding for climate change adaptation in the water sector; the existing policies such as between sectors such as the Farm Bill and Energy Future Bill are mal-aligned and should be aligned with the water sector; and negative environmental externalities including factors that exacerbate climate change should be incorporated into
\end{abstract}


the true cost of water so we can more accurately conduct ecosystem valuation and, thus, address the true economic and environmental cost of climate change on the Great Lakes and our greatest water resources. This paper has not previously been published.

\section{Keywords}

Climate Change, Water Sustainability, Economic Valuation, Interdependence, Water-Agriculture-Energy Nexus and Climate Disruptions, Great Lakes

\section{Introduction}

The Great Lakes are vast yet vulnerable. At a critical threshold, the Great Lakes are currently facing consequential environmental challenges from climate change. Degradation of water quality and quantity due to climate change has already altered the capacity of the Great Lakes region to produce agriculture, decreased the ability to generate energy, and exacerbated environmental stressors such as toxic uptake. Yet there is a great lapse in our understanding of the effects of climate change on the Great Lakes and the associated environmental and economic risks.

The Laurentian Great Lakes are the world's largest surface freshwater resource. The Great Lakes, bordered by the United States and Canada, hold 25\% of the planet's total freshwater [1]. Driven by freshwater as its engine for economic growth, the Great Lakes region constitutes the fourth largest economy in the world [2].

The Great Lakes region produces $\$ 4.6$ trillion in economic output [3]. It produces 33\% of US Gross Domestic Product [4] and 24\% of US exports [5]. As freshwater becomes more scarce due to over consumption, burgeoning population, and pollution, it is critical to steward the Great Lakes water resources with a new understanding of the relationship between economic growth and environmental stress.

The Great Lakes region is at a turning point in economic development and approaching environmental thresholds, and is demonstrating national and international leadership in recognizing, addressing, and advancing the understanding of economic and environmental interdependence, and how to steward that interdependence for long-term prosperity and sustainability. The eight US states and two Canadian provinces of the Great Lakes join an increasing number of international watersheds and nations that are seeking "ways to move beyond economic growth patterns that diminish natural resources to those that support long-term sustainable development" [4].

The purpose of this article is to highlight the intersection of economic risks and water risks based on the newest scientific evidence of the effects of climate change on freshwater resources in the Great Lakes. To establish this intersection, the paper is organized to move in a logical progression from 1) the economic 
valuation of ecosystem services in the Great Lakes, including water assets and water-dependent employment, to 2) the effects of climate change on water resources and agricultural production, to 3 ) the effects of climate change on water resources and energy production, to 4) a conclusion by way of suggesting ways forward that protect the region's most valuable natural asset, the waters of the Great Lakes. It concludes by suggesting a range of policy-based strategies to incorporate climate models into water restoration projects. The intent is to take the mystery out of interpreting science-based evidence on the effects of climate change on the Great Lakes, and make it practical and feasible to incorporate climate information into protection and restoration efforts.

\section{Methodology}

To conduct this study, the author(s) completed 32 interviews with leading water scientists, climate scientists, and related experts across the Great Lakes region in the US and Canada, including 21 specialists in Great Lakes ecosystem health comprised of biologists, microbiologists, limnologists, hydrologists, and climatologists, as well as 11 leading economists and policy analysts on climate change in the Great Lakes. To comply with the International Review Board exemption for Human Subjects Research, the identity of the expert interviewees and their related institutions or agencies are protected consistent with legal regulations and ethical standards. In addition to the 32 indepth interviews of leading science experts and extensive curative archival research on over 200 articles on climate change in the Great Lakes, this study replicated the descriptive statistics of the leading articles on economic valuation and employment statistics, and it cites only those few studies that could be replicated and verified using the Great Lakes Restoration Initiative Report to Congress and the President by the Environmental Protection Agency [6] or the Quarterly Census of Employment and Wages by the Bureau of Labor Statistics at the United States Department of Labor [7].

\section{Ecosystem Valuation}

Ecosystem valuation of the Great Lakes shows that there are more than 1.5 million jobs that are directly related to water resources in the Great Lakes. Those jobs generate over $\$ 62$ million in wages [5]. The jobs are primarily in the large sectors of manufacturing, agriculture, and energy, the main drivers of economic growth in the region. The employment statistics include approximately a million jobs in manufacturing, 217,635 jobs in tourism, 118,550 jobs in shipping, 118,430 jobs in fishing and related food production, 38,085 jobs in science and engineering, and 20,983 in energy, utilities, and mining [5].

In addition to ecosystem valuation as measured by jobs and wages, the value of the Great Lakes has also been estimated for its ecosystem services value and restoration value, in which the economic value of the Great Lakes is shown to be substantial. The Brookings Institution's Great Lakes Economic Initiative estimates that the Great Lakes have a direct economic benefit of $\$ 50$ billion in 
long-term benefits and $\$ 30$ - $\$ 50$ billion in short-term multiplier benefits. Included in the estimates of this restoration value are the direct benefit of \$7 - 12 billion from tourism, fishing and recreation; the direct economic benefit of $\$ 12$ 19 billion in property values; and the direct savings of $\$ 50-\$ 125$ million for municipalities providing drinking water [4]. With an additional $\$ 30-\$ 50$ billion in multiplier effects [4], which should not be underestimated in importance or amount, the restoration value of the Great Lakes is over $\$ 100$ billion in economic benefits.

The Great Lakes ecosystem continues to face climate threats that jeopardize its economic vitality and environmental sustainability. If these threats are not addressed, the Great Lakes region stands to lose it economic engine. Without the water-driven economic engine, the Great Lakes region will lose its 1.5 million water-related jobs, $\$ 62$ million in wages, $\$ 100$ billion related ecosystem valuation, a substantial part of its $\$ 4.6$ trillion in economic output, its influence as the fourth largest economy in the world, its national and international leadership in the water sector, and immeasurable multiplier benefits.

The economy viability and prosperity of the Great Lakes region are largely possible because of the abundance of rivers and lakes as arteries and inputs for the auto industry, beverage industry, steel industry, paper manufacturing, agriculture, mining, heating and cooling of factories and power plants, transporting raw materials and shipping products across the region and from the Midwest to the ocean, and historically for dumping the toxic waste products of industry and the toxic fertilizers of agriculture into the waterways. The environmental damage of this toxic waste disposal became undeniable when the surface of rivers in the Great Lakes region ignited on fire, including the Cuyahoga River, Buffalo River, Rouge River, Detroit River, and Chicago River, among others [8].

To protect the economic viability of the Great Lakes states, over $\$ 300$ million has been spent annually by the United States Federal Government to protect and restore the waters of the Great Lakes basin. The Great Lakes Restoration Initiative (GLRI), which administers the $\$ 300$ million, has received widespread bipartisan support to sustain the ecosystem services. However, the current administration has proposed a $97 \%$ cut in the GLRI funding, which would dismiss efforts to address climate change, degrade water resources, and derail economic development in the region.

\section{Agriculture, Water, and Climate Change in the Great Lakes}

Agriculture is the largest and most essential component of the Great Lakes economy. It generates $\$ 15$ billion annually in food crops [5]. The agricultural sector is highly dependent on water resources including lake levels, precipitation, temperature, and evaporation, all of which are significantly altered by climate change.

Climate change is expected to increase temperatures and increase severity of droughts, punctuated by incidents of extreme storms and floods, which will alter 
the capacity and reliability of crop production. The extreme weather events will also increase erosion and the loss of nutrients from fields, and increase the run-off of toxic chemical pesticides and fertilizers. For the Great Lakes overall, climate models predict a warmer and wetter climate with more variability. In specific, temperatures in the Great Lakes are expected to increase $3^{\circ} \mathrm{C}-7^{\circ} \mathrm{C}$ in the next $60-70$ years [9]. Precipitation models vary greatly and predict a range of change from a decrease in precipitation by $9 \%$ to an increase in precipitation by $21 \%$ [9], this wide variability coupled with the inconclusiveness of predictions make it difficult for planning and policy to address climate change in the agricultural sector. In addition to temperatures and precipitation, the amount of evaporation affects the efficiency of water use in the agricultural sector as well as the lake levels, and evaporation is expected to increase significantly, 19\% - 36\% in the Great Lakes [9], due to increases in temperature from climate change. The growing season is expanding and the global demand for food crops is increasing, which will present an opportunity to increase agricultural production, if the extreme weather variability and sporadic droughts and crop damage can be addressed. The growing season has already increased by four weeks in the Great Lakes region and it is expected to increase up to nine weeks in the upcoming decades [9]. An increased growing season will also will put more pressure on the land and water resources of the Great Lakes, as well as increase the chemical pesticides and fertilizers used, and there are no policies in place to manage this potential climate variability and possible agricultural growth.

Most of the agricultural production is in grains, soybeans, dairy, livestock, and corn for food, animal feed, and bio fuel. The Great Lakes basin accounts for seven percent of all agricultural production in the United States and 25 percent in Canada [10]. The high level of agricultural production requires large quantities of water be extracted from the Great Lakes hydrological system and ecosystem. The water withdrawals for agriculture are more than 23 billion liters per day (620 million gallons per day) for crop irrigation [11]. Most of the water used for agriculture is considered a consumptive use, meaning the water is not returned to the hydrological system, and the water that is returned to the system is often highly polluted with animal waste or toxic chemical fertilizers and pesticides.

Climate change at the national and global levels also have direct effects the environmental tax of the Great Lakes. The extreme droughts in other parts of the United States and global water scarcity at the international level will increase the demands on intense agriculture in the Great Lakes region, as a function of our greatest natural asset and economic input, freshwater. If this freshwater is severely degraded, it will jeopardize the capacity of agriculture to continue to thrive and prosper.

\section{Energy, Water, and Climate Change in the Great Lakes}

The Great Lakes region produces enough energy to power approximately 45 mil- 
lion homes. It is technically an energy independent region, although it imports and exports different forms of energy such as coal depending on needs and price. There are over 580 power plants in the Great Lakes region [12]. The large amount of energy they produce is primarily from coal-fired power plants (40\%) and natural gas power plants (30\%), which generate about $70 \%$ of the region's energy [13] and contribute the majority of the region's carbon emissions [12]. The energy powers the manufacturing sector as well as the energy-intensive practices of industrial-scale agriculture, particularly energy for pumping water for irrigation.

The energy sector is highly dependent on freshwater resources. It takes large quantities of water to produce energy: to extract energy resources through mining or hydrologic fracturing; to clean energy resources or separate energy resources from ore, shale, clay, sand, or bitumen; and to heat and cool power plants. The largest water-users in the energy sector are coal-fired thermoelectric power plants, which withdraw 16 billion gallons (60,000 megaliters) per day [12]. Much of the water used to produce energy is considered a consumptive use, the water discharged after energy production is highly polluted with toxic substances and cannot be reintroduced into the environment without disrupting and degrading the ecosystem.

In addition to substantial carbon missions from the energy sector that contribute climate change, the inverse is a reality in the Great Lakes: climate changes poses numerous threats to the energy sector such as rising water temperatures and decreasing water supplies, including declining lake levels in the Great Lakes. Water temperatures and evaporation rates are expected to rise in the region, which statistical models predict will decrease lake levels by a drastic 8.2 feet ( 2.5 meters) by 2090 [14]. The higher water temperatures will make the intake water warmer at power plants, which will decrease cooling efficiency and safety. Warmer water intake has already been documented to be 8 C in Lake Michigan [13], which greatly decreases cooling efficiency for power plants. Warmer intake water also results in warmer discharge water from power plants, which will further degrade ecosystems and will likely push power plants into non-compliance with environmental policies on discharge water. The loss of water to higher levels of evaporation and consumption will result in long-term consequences for lowering lake levels. The lake level of Lake Michigan has already been documented to decrease up to six feet (2 meters) during low years, which has resulted in many power plants shutting down temporarily or permanently, and other power plants regularly violating permits. The lower water levels in the Great Lakes will require many drinking water intake locations and power plants locations near the shores of the Great Lakes to relocate.

\section{Conclusion: A Way Forward}

As a harbinger of change, the Great Lakes region is approaching an important threshold in needing to sustain its freshwater assets in order to maintain its 
economic prosperity. This reality is particularly evident in the large economic sectors of agriculture and energy, which are highly dependent on the freshwaters of the Great Lakes. A ripple of stakeholders and decision-makers are working to move from an economic model of consumption to one of conservation, or at least recognizing the relationship of the economy to the water assets upon which it depends.

Three important conclusions emerged from this investigation, particularly regarding the intersection of economic risks and water risks highlighted by the 32 experts interviewed. Conclusion one: policies to address climate change in the Great Lakes need to restore the proposed $97 \%$ reduction in federal funds for restoring and sustaining the Great Lakes. The loss of this federal funding jeopardizes the economic viability of agriculture and energy in the region, as well as diminishes the other $\$ 100$ billion in ecosystem valuations for employment, conservation, tourism, and shipping, among other benefits. Conclusion two: the agriculture sector and energy sector need to align their practices with water policies for climate mitigation and adaptation. Evidence shows that policies are currently non-existent or mal-aligned. As these policies are developed or aligned, they should incentivize water efficiency in the agriculture and energy. Conclusion three: include liabilities and negative environmental externalities into the true cost of using water and maximize efforts to reduce pollution such as increasing compliance with the US Clean Water Act that requires toxic pollution to be reduced to zero. This would include enforcing existing laws and governing water through the Public Trust Doctrine, which would increase the demand for the mitigation of both economic and environmental risks.

There are hundreds of organizations, businesses, universities, and thousands of citizens actively working to restore the Great Lakes and to recognize the interdependence of the economy with the vital freshwater resources of the region. For example, in research and education, the Great Lakes region has "the world's leading network of universities" [4]; twenty of the top 100 research universities are located in the Great Lakes region [3]; and most of them have freshwater-specific research and academic programs, including the School of Freshwater Sciences at University of Wisconsin-Milwaukee, Marquette University, Michigan State University, University of Michigan, University of Wisconsin-Madison, University of Minnesota, and numerous other universities in the region.

Business and entrepreneurship in the region also demonstrate an emphasis on the comparative advantage of freshwater resources. There are thousands of businesses that are focused on water-related production and consumption. For example, the Milwaukee Water Council coordinates a collection of over 120 water-related businesses in the Greater Milwaukee Region, and supports business development, economic growth, attracting new businesses and investments, and financing entrepreneurial endeavors in the region based specifically on the proximity, availability, and proclivity to focus on the Great Lakes freshwater resources. Accordingly, the Brookings Institution's Great Lakes Economic Initiative makes the 
case that "The Great Lakes and its waterways offer a tremendous opportunity for reinvigorating the economy of the region, and boosting the competitiveness of the nation as a whole" [4].

The economic prosperity and environmental sustainability of the Great Lakes are not juxtaposed or antithetical; they are interdependent. Freshwater is the engine of growth in the Great Lakes region; it generates over 1.5 million in jobs and produces $\$ 4.6$ trillion in economic output [3], most of which is in agriculture and energy-intensive manufacturing.

Although the Great Lakes are vast, they are also fragile ecosystems and vulnerable to the effects of climate change. The impacts of climate change are already consequential in the Great Lakes. As a way forward, the case of the Great Lakes, the world's greatest surface freshwater resource and one of the world's largest economies, suggests that we recognize the interdependence of the economy with the environment, and that we steward both with an understanding of the inextricable link between prosperity and sustainability.

\section{Acknowledgements}

The author is grateful for the funding and forward-thinking of Fulbright Scholar Program, as well as Ellen Amster, Karen Bird, Carolyn Johns, McMaster University Ontario Canada and University of Wisconsin Milwaukee USA.

\section{Conflicts of Interest}

The author declares no conflicts of interest regarding the publication of this paper.

\section{References}

[1] National Oceanic and Atmospheric Administration (2018) Great Lakes Environmental Research Laboratory, United States Department of Commerce. https://www.noaa.gov/ https://coastwatch.glerl.noaa.gov

[2] Kavcic, R. (2014) Great Lakes Region: North America's Economic Engine. Special Report by Bank of Montreal, 1-9.https://economics.bmocapitalmarkets.com/

[3] Katz, B. and Josh, H. (2011) The Great Lakes Can Lead the World. The Brookings Institution, 1-4. https://www.brookings.edu/opinions/

[4] Austin, J.C., Soren, A., Paul, C. and Litan, R.E. (2007) Healthy Water, Strong Economy: The Benefits of Restoring the Great Lakes Ecosystem. The Brookings Institution Great Lakes Economics, 7, 1-16.

[5] Vaccaro, L. and Jennifer, R. (2011) Vital to Our Nation's Economy: Great Lakes Jobs. Michigan Sea Grant, 1-7. https://www.fws.gov/glri/documents/2011GreatLakesJobsReport.pdf

[6] United States Environmental Protection Agency (2016) Great Lakes Restoration Initiative Report to Congress and the President 2016. https://www.epa.gov/great-lakes-funding/great-lakes-restoration-initiative-glri

[7] (2016) Quarterly Census of Employment and Wages. Bureau of Labor Statistics, United States Department of Labor. https://www.bls.gov/cew/ 
[8] (2015) Great Lakes: From Rustbelt to Bluebelt. The Economist. https://www.economist.com/united-states/2015/07/30/from-rustbelt-to-bluebelt

[9] Intergovernmental Panel on Climate Change (2014) Fifth Assessment Report. https://www.ipcc.ch/report/ar5/

[10] Jim, C., Mann, A., LeBaron, A., Hunt, S., Kruzansky, R., Hallfrisch, M., Black, L., Staples, J., Jostenski, D., Bedard, M.-O. and Pfeiffer, S. (2015) Great Lakes Regional Water Use. Great Lakes-St. Lawrence River Basin Water Resources.

[11] Great Lakes Commission. http://www.projects.glc.org/waterusedata.pdf

[12] Victoria, P. (2011) Integrating Energy and Water Resources Decision Making in the Great Lakes Basin. No. 9, Great Lakes Commission, 9-22.

[13] Great Lakes Commission (2018) Des Grands Lacs. https://www.glc.org/about/board-of-directors/

[14] Lofgren, B.M., Quinn, F.H., Clites, A., Assel, R., Eberhardt, A. and Luukkonen, C. (2002) Evaluation of Potential Impacts on Great Lakes Water Resources Based on Climate Scenarios on Two GCMs. Journal of Great Lakes Research, 28, 537-554. https://doi.org/10.1016/S0380-1330(02)70604-7 